Article

\title{
Investigation of the Optimum Mg Doping Concentration in p-Type-Doped Layers of InGaN Blue Laser Diode Structures
}

\author{
Chibuzo Onwukaeme and Han-Youl Ryu * (D) \\ Department of Physics, Inha University, 100 Inha-ro, Michuhol-gu, Incheon 22212, Korea; \\ hyginusonwuka@gmail.com \\ * Correspondence: hanryu@inha.ac.kr; Tel.: +82-32-860-9200
}

Citation: Onwukaeme, C.; Ryu, H.-Y Investigation of the Optimum $\mathrm{Mg}$ Doping Concentration in p-TypeDoped Layers of InGaN Blue Laser Diode Structures. Crystals 2021, 11, 1335. https://doi.org/10.3390/ cryst11111335

Academic Editors: Degang Zhao and Baoping Zhang

Received: 18 October 2021

Accepted: 30 October 2021

Published: 1 November 2021

Publisher's Note: MDPI stays neutral with regard to jurisdictional claims in published maps and institutional affiliations.

Copyright: (c) 2021 by the authors. Licensee MDPI, Basel, Switzerland. This article is an open access article distributed under the terms and conditions of the Creative Commons Attribution (CC BY) license (https:// creativecommons.org/licenses/by/ $4.0 /)$.

\begin{abstract}
In GaN-based laser diode (LD) structures, Mg doping in p-type-doped layers has a significant influence on the device performance. As the doping concentration increases, the operation voltage decreases, whereas the output power decreases as a result of increased optical absorption, implying that optimization of the $\mathrm{Mg}$ doping concentration is required. In this study, we systematically investigated the effect of the $\mathrm{Mg}$ doping concentration in the AlGaN electron-blocking layer (EBL) and the AlGaN p-cladding layer on the output power, forward voltage, and wall-plug efficiency (WPE) of InGaN blue LD structures using numerical simulations. In the optimization of the EBL, an $\mathrm{Al}$ composition of $20 \%$ and an $\mathrm{Mg}$ doping concentration of $3 \times 10^{19} \mathrm{~cm}^{-3}$ exhibited the best performance, with negligible electron leakage and a high WPE. The optimum $\mathrm{Mg}$ concentration of the p-AlGaN cladding layer was found to be $\sim 1.5 \times 10^{19} \mathrm{~cm}^{-3}$, where the maximum WPE of $38.6 \%$ was obtained for a blue LD with a threshold current density of $1 \mathrm{kA} / \mathrm{cm}^{2}$ and a slope efficiency of $2.1 \mathrm{~W} / \mathrm{A}$.
\end{abstract}

Keywords: laser diode; blue laser; high-power laser; InGaN; nitride semiconductor

\section{Introduction}

After the first development of nitride laser diodes (LDs) in 1996 [1] and first demonstration of blue LDs in 2001 [2] by Nichia, the performance of blue LDs has improved considerably. To date, InGaN/GaN-based blue LDs have attracted significant attention for use in light sources for laser displays [3-5], laser-based white lighting [6-8], free-space or underwater communications [9-11], and laser-based materials processing [12-14]. In recent years, high-power operation of InGaN blue LDs with $>5 \mathrm{~W}$ output power in a single chip has been demonstrated, mainly by company research groups such as Nichia, Osram, and Sony $[3,4,12]$. They also reported the low-threshold and high-efficiency operation of blue LDs with a threshold current density $\left(J_{t h}\right)<1 \mathrm{kA} / \mathrm{cm}^{2}$, slope efficiency $(\mathrm{SE})>2 \mathrm{~W} / \mathrm{A}$, and wall-plug efficiency $(\mathrm{WPE})>40 \%[3,12]$. Very recently, a university research group at Xiamen university also reported comparable performance of a blue LD with a $J_{t h}$ of $\sim 1 \mathrm{kA} / \mathrm{cm}^{2}$ and an SE of $1.8 \mathrm{~W} / \mathrm{A}$ [15].

Despite the remarkable progress in the development of high-power and high-efficiency blue LDs, the performance of InGaN blue LDs is still inferior to that of GaAs-based infrared LDs, which demonstrated a WPE of even more than 70\% [16]. Mg doping in p-typedoped layers of GaN-based LDs is one of the main factors limiting the WPE. Owing to the high acceptor activation energy of $\mathrm{Mg}$ in (Al)GaN and the low mobility of hole carriers, the resistivity of p-type-doped layers in GaN-based LD structures is considerably larger than that of n-type layers, which results in a high operation voltage. To improve the conductivity of the p-AlGaN cladding layer and prevent electron leakage over the AlGaN electron-blocking layer (EBL), high-concentration $\mathrm{Mg}$ doping is required to increase the hole concentration. The low conductivity of the p-type layers is one of the main reasons limiting the WPE of GaN-based LDs [17,18]. 
However, optical absorption in heavily-doped p-type layers is one of the main causes of internal loss in GaN-based LDs [18-24]. The absorption coefficient of Mg-doped p-type layers increases with increasing doping concentration as a result of free-carrier absorption $[25,26]$. The absorption coefficient of p-type layers in GaN-based LDs has been reported to be in several tens of $\mathrm{cm}^{-1}$, which could significantly decrease the SE and, hence, the laser output power of an LD. To reduce the modal loss associated with p-type doping, a thick undoped waveguide layer has been employed between multiple-quantum-well (MQW) active layers and a p-AlGaN cladding layer [19,21-24]. The optical loss can also be decreased by decreasing the $\mathrm{Mg}$ doping concentration in the $\mathrm{p}$-type layers. However, the operation voltage could be increased as the thickness of the undoped layer increases or the $\mathrm{Mg}$ doping concentration of the p-type layers decreases. Hence, there is a tradeoff relationship between the operation voltage and laser output power with variation in the doping concentration of $\mathrm{Mg}$, which implies that there exists an optimum $\mathrm{Mg}$ doping concentration in the p-type-doped layers in GaN-based LD structures. Meanwhile, there is a wide variation in the reported $\mathrm{Mg}$ doping concentration, ranging from $<1 \times 10^{18}$ to $5 \times 10^{19} \mathrm{~cm}^{-3}[23,24,27-30]$, and there has been a lack of studies on the optimum $\mathrm{Mg}$ doping concentration in the p-type layers of InGaN blue LD structures.

In this study, we investigated the optimum $\mathrm{Mg}$ doping concentrations in the p-type AlGaN EBL and cladding layers of InGaN blue LD structures using numerical simulations. For the simulation of the LD device characteristics, we employed a simulation software application, LASer Technology Integrated Program (LASTIP), produced by Crosslight Co. [31]. Regarding the optimization processes of this study, the thickness of the waveguide layers below and above the MQW was first optimized to obtain a high optical confinement factor (OCF) and low-threshold operation. Next, we investigated the effects of the Al composition and $\mathrm{Mg}$ doping concentration in the $\mathrm{p}$-AlGaN EBL on the electron leakage current and LD characteristics. Finally, the Mg doping concentration in the p-AlGaN cladding layer was optimized to obtain the highest WPE for high-power operation.

\section{Materials and Methods}

\subsection{Laser Diode Structure}

Figure 1a schematically shows the blue LD structure used in the simulation of this study. The LD epitaxial layer structures were composed of a $1-\mu \mathrm{m}$ thick $\mathrm{n}-\mathrm{Al}_{0.04} \mathrm{Ga}_{0.95} \mathrm{~N}$ cladding layer, an $\mathrm{n}-\mathrm{In}_{0.02} \mathrm{Ga}_{0.98} \mathrm{~N}$ lower waveguide (LWG), MQW active region, an $\mathrm{In}_{0.02} \mathrm{Ga}_{0.98} \mathrm{~N}$ upper waveguide (UWG), a 15-nm thick p-AlGaN EBL, a $0.6-\mu \mathrm{m}$ thick p$\mathrm{Al}_{0.04} \mathrm{Ga}_{0.95} \mathrm{~N}$ cladding layer, and a $20-\mathrm{nm}$ thick $\mathrm{p}-\mathrm{GaN}$ contact layer grown on a GaN substrate. The active region consisted of two 3-nm $\operatorname{In}_{0.15} \mathrm{Ga}_{0.85} \mathrm{~N} \mathrm{QW}$ layers separated by a $10-\mathrm{nm} \mathrm{In}_{0.02} \mathrm{Ga}_{0.98} \mathrm{~N}$ barrier layer. For this MQW structure, the emission wavelength of the LD was $450 \mathrm{~nm}$ at $25^{\circ} \mathrm{C}$. A recent study revealed that a blue LD structure with two InGaN QWs exhibits the best performance [15]. The QW and barrier layers in the active region were undoped. The doping concentrations of the n-type doped layers, such as the $n-G a N$ substrate, the $n-A l G a N$ cladding layer, and the $\operatorname{In}_{0.02} G_{0.98} \mathrm{~N}$ LWG, were all assumed to be $5 \times 10^{18} \mathrm{~cm}^{-3}$. While the LWG was doped with an n-type dopant, the UWG was left undoped to avoid significant optical absorption loss, which might otherwise be caused by p-type doping [19,21-24]. However, the undoped MQW and UWG regions were assumed to have an unintentionally doped background electron concentration of $5 \times 10^{16} \mathrm{~cm}^{-3}[23,29]$. The doping concentration of the $\mathrm{p}-\mathrm{GaN}$ contact layer was set to $2 \times 10^{19} \mathrm{~cm}^{-3}$. 
(a)

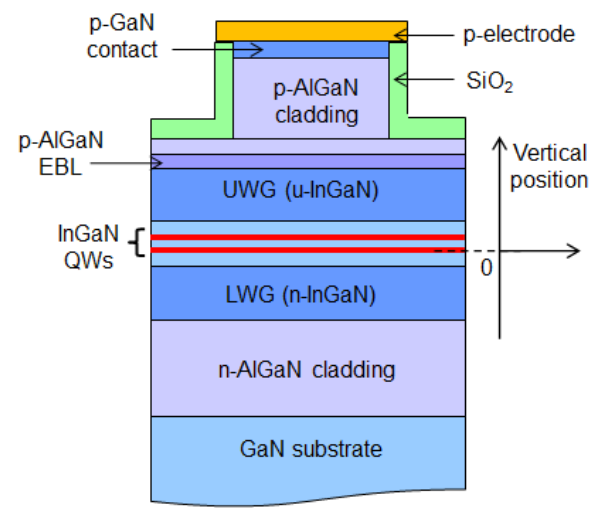

(b)



Figure 1. (a) Schematic of the simulated LD structure. (b) Vertical profiles of the refractive index (left vertical axis) and the normalized wave intensity of the lasing mode (right vertical axis) of the simulated LD structure. The origin of the vertical position corresponds to the bottom interface of the $\mathrm{n}$-side QW, as indicated by the dotted lines in (a).

In the simulated LD structure, the UWG was positioned between the MQW and EBL. This layer arrangement has been known to be advantageous for reducing the absorption loss caused by the Mg-doped EBL [21-24] and preventing the diffusion of Mg dopant into the active region [32-34]. The LD chip structure had the form of a broad area ridge waveguide with a ridge width of $30 \mu \mathrm{m}$ and a cavity length of $1200 \mu \mathrm{m}$ for high-power operation. The reflectivities of the front and rear facet were assumed to be $5 \%$ and $95 \%$, respectively. In the simulation, we investigated the LD characteristics by varying the thickness of the LWG and UWG, the composition and doping concentration of the EBL, and the doping concentration of the p-AlGaN cladding layer.

\subsection{Simulation Methods}

The device characteristics, such as the output power versus current relation ( $L-I$ curve) and the forward voltage versus current relation ( $V-I$ curve), were simulated using LASTIP. It self-consistently solves $\mathrm{QW}$ band structures, radiative and nonradiative carrier recombination, the drift and diffusion equation of carriers, and the photon rate equations [31]. The built-in polarization fields induced by spontaneous and piezo-electric polarizations at the hetero-interfaces, such as InGaN/GaN, AlGaN/GaN, and InGaN/AlGaN, were also included using the model described in Ref. [35], assuming a 50\% compensation for the polarization fields [36,37]. Then, the strength of the polarization fields at the interfaces between the $\mathrm{In}_{0.15} \mathrm{Ga}_{0.85} \mathrm{~N}$ QW and GaN barrier was approximately $1 \mathrm{MeV} / \mathrm{cm}$, which roughly corresponds to the reported internal electric fields of $\operatorname{In}_{0.15} \mathrm{Ga}_{0.85} \mathrm{~N} / \mathrm{GaN}$ MQWs $[38,39]$. The conduction band offset of the hetero-barriers was set to be 0.7 [17]. For this band offset value, the corresponding barrier heights of the conduction band between $\operatorname{In}_{0.15} \mathrm{Ga}_{0.85} \mathrm{~N} / \mathrm{In}_{0.02} \mathrm{Ga}_{0.98} \mathrm{~N}$ QWs and $\operatorname{In}_{0.02} \mathrm{Ga}_{0.89} \mathrm{~N} / \mathrm{Al}_{0.2} \mathrm{Ga}_{0.8} \mathrm{~N}$ EBL were 430 and $295 \mathrm{meV}$, respectively. The mobility model described in Refs. [40-42] was used for the mobility of electrons, which resulted in an electron mobility of $\sim 500 \mathrm{~cm}^{2} / \mathrm{Vs}$ for n-GaN with a doping concentration of $1 \times 10^{18} \mathrm{~cm}^{-3}$. The hole mobilities in the InGaN and (Al)GaN layers were assumed to be 5 and $15 \mathrm{~cm}^{2} / \mathrm{Vs}$, respectively [31,41].

Using the refractive index data of $\mathrm{GaN}, \mathrm{AlGaN}$, and $\mathrm{InGaN}$ alloys at $450 \mathrm{~nm}$ from Refs. [25,43-45], the refractive indices of the $\mathrm{GaN}$ layer, $\mathrm{Al}_{0.04} \mathrm{GaN}$ cladding layers, and $\mathrm{In}_{0.02} \mathrm{GaN}$ waveguides were chosen to be $2.48,2.46$, and 2.50 , respectively. Figure $1 \mathrm{~b}$ shows the profiles of the refractive index and wave intensity of the lasing mode as a function of the vertical position when the thicknesses of both the LWG and UWG are $120 \mathrm{~nm}$, and the $\mathrm{Al}$ composition of the EBL is $20 \%$. The origin of the vertical position corresponds to the bottom interface of the n-side QW. As shown in Figure 1b, the lasing mode is symmetrically distributed and centered at the QW layers to obtain a high OCF value. In this case, the 
OCF was calculated to be $\sim 1.5 \%$. This OCF value is similar to that of previously reported InGaN blue LD structures with double QW layers, with a similar QW thickness [22,24,28]. To model the optical absorption loss, we adopted a first-principle calculation model for free-carrier absorption derived from Ref. [26], which showed an absorption cross-section of $\sim 0.6 \times 10^{-18} \mathrm{~cm}^{2}$ for both the donor and acceptor dopants. According to Ref. [26], both free holes and acceptor-bound holes contribute to the optical absorption process in the p-type-doped layers. Therefore, the absorption coefficient could be obtained by multiplying the absorption cross-section by the Mg doping concentration. For example, the absorption coefficient of n-type layers with a doping concentration of $5 \times 10^{18} \mathrm{~cm}^{-3}$ and that of a p-type layer with a doping concentration of $2 \times 10^{19} \mathrm{~cm}^{-3}$ were set as 3 and $12 \mathrm{~cm}^{-1}$, respectively. In addition to the free-carrier absorption, the background absorption coefficient, which might account for the scattering losses or absorption in metals, was assumed to be $2 \mathrm{~cm}^{-1}$.

Owing to the high acceptor activation energy of $\mathrm{Mg}$, the actual hole concentration in the p-type-doped region would be significantly lower than the Mg doping concentration. In the simulation, the incomplete ionization of $\mathrm{Mg}$ acceptor atoms in the p-type-doped layers was included, and the acceptor ionization energy in AlGaN was assumed to scale linearly from $170 \mathrm{meV}(\mathrm{GaN})$ to $470 \mathrm{meV}(\mathrm{AlN})[17,46]$. For an acceptor doping concentration of $N_{a}$, the ratio of hole concentration $p$ to $N_{a}$ is given by [47]

$$
\frac{p}{N_{a}}=1-\frac{1}{1+g_{a}^{-1} \exp \left[\left(E_{F}-E_{a}\right) / k T\right]}
$$

where $E_{F}, E_{a}, k$, and $T$ are the Fermi energy level, acceptor ionization energy, Boltzmann constant, and the absolute temperature, respectively. $g_{a}$ is called a degeneracy factor, which is normally taken as 4 for acceptors. The Lastip program calculated the actual hole concentration in Mg-doped region using Equation (1). Figure 2 shows the hole concentration and ratio of ionized $\mathrm{Mg}$ acceptors at the $\mathrm{p}-\mathrm{Al}_{0.05} \mathrm{GaN}$ cladding layer as a function of the $\mathrm{Mg}$ doping concentration. As the $\mathrm{Mg}$ doping concentration increased from $2 \times 10^{18}$ to $5 \times 10^{19} \mathrm{~cm}^{-3}$, the hole concentration increased slowly from $0.07 \times 10^{18}$ to $0.37 \times 10^{18} \mathrm{~cm}^{-3}$ and the ratio of ionized $\mathrm{Mg}$ acceptors decreased from $3.7 \%$ to $0.75 \%$. As a result of the low ionization ratio of $\mathrm{Mg}$, the actual hole concentration was far below $10^{18} \mathrm{~cm}^{-3}$ in AlGaN, even for a high $\mathrm{Mg}$ doping concentration $>10^{19} \mathrm{~cm}^{-3}$.

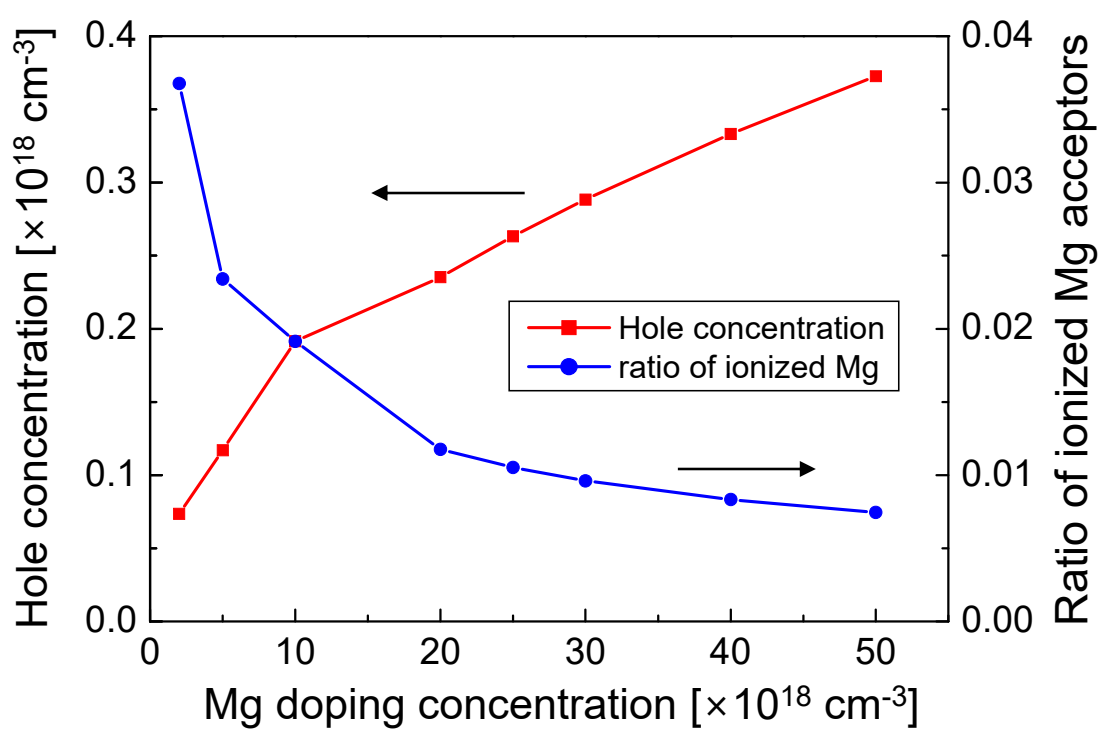

Figure 2. Hole concentration (right vertical axis) and the ratio of ionized $\mathrm{Mg}$ acceptor atoms (left vertical axis) for the simulated LD structure as a function of $\mathrm{Mg}$ doping concentration in the p-AlGaN cladding layer. 
In the carrier recombination model of LASTIP, the radiative recombination rate is calculated by integrating the spontaneous emission spectrum with a Lorentzian line-shape function. The Shockley-Read-Hall (SRH) recombination lifetime was assumed to be $50 \mathrm{~ns}$. However, the effect of SRH recombination on the threshold current was found to be almost negligible when the SRH lifetime was longer than $10 \mathrm{~ns}$. The lasing threshold of the InGaN blue LDs is strongly influenced by the Auger recombination coefficient $(C)[18,45]$. In the current simulations, $C$ was chosen to be $2 \times 10^{30} \mathrm{~cm}^{-6} / \mathrm{s}$ for the simulated blue LD to exhibit a $J_{t h}$ of $\sim 1 \mathrm{kA} / \mathrm{cm}^{2}$. Figure 3 a shows the $L-I$ curve of the simulated LD structure using the parameters described above. Here, the thicknesses of the LWG and UWG were $120 \mathrm{~nm}$, the Al composition and doping concentration of the EBL were $20 \%$ and $3 \times 10^{19} \mathrm{~cm}^{-3}$, respectively, and the doping concentration of the $\mathrm{p}$-AlGaN cladding layer was $1.5 \times 10^{19} \mathrm{~cm}^{-3}$. In the subsequent section, we show that these values are close to the optimum values to achieve the highest WPE. The $L-I$ curve in Figure 3 a shows a threshold current of $350 \mathrm{~mA}$ and an SE of $2.1 \mathrm{~W} / \mathrm{A}$. The $J_{\text {th }}$ value was estimated to be $0.98 \mathrm{kA} / \mathrm{cm}^{2}$ by dividing the threshold current by the cavity length and the ridge width. These $J_{t h}$ and SE values approximately correspond to those recently reported for high-power blue LDs $[4,14,15]$. Figure $3 \mathrm{~b}$ shows the WPE as a function of injection current. A peak WPE of $\sim 38 \%$ was obtained at $2 \mathrm{~A}$, and a high WPE $>35 \%$ was maintained up to $3.6 \mathrm{~A}$. In the simulation, the temperature of the LD structures was set at $298 \mathrm{~K}$ and self-heating effects were not considered. Therefore, the simulation results correspond to the pulsed operation condition with negligible thermal effects.
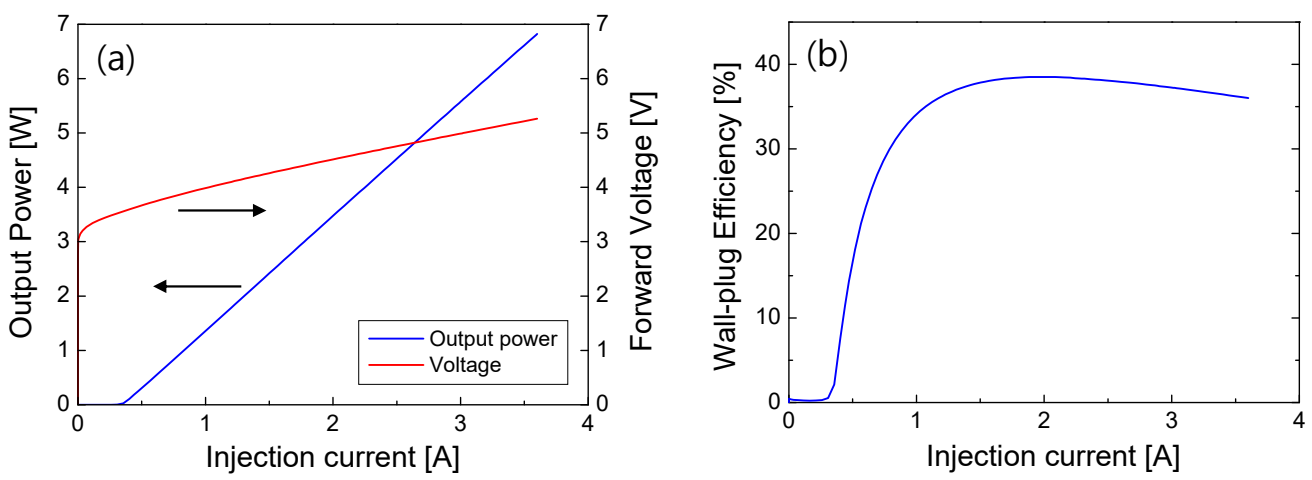

Figure 3. (a) Output power versus current $(L-I)$ and forward voltage versus current $(V-I)$ curves for the simulated reference LD structure. (b) Wall-plug efficiency (WPE) as a function of injection current for the simulated reference LD.

\section{Results and Discussion}

\subsection{Optimum Thickness of LWG and UWG}

The effects of the LWG and UWG on the OCF and lasing threshold were investigated to find the optimum waveguide thickness. Figure 4 shows the OCF and lasing threshold as a function of the waveguide thickness. In the simulation, the thicknesses of the LWG and UWG were simultaneously varied. Initially, the OCF increased with the waveguide thickness from 60 to $120 \mathrm{~nm}$ as a result of increased optical confinement in the $\mathrm{In}_{0.02} \mathrm{Ga}_{0.98} \mathrm{~N}$ LWG and UWG layers. When the thickness was larger than $120 \mathrm{~nm}$, the OCF began to decrease because the portion of the lasing mode profile within the QW layers decreased with the waveguide thickness for sufficiently thick waveguides. Therefore, the highest OCF was obtained for the LWG and UWG thickness of $120 \mathrm{~nm}$. As shown in Figure 4, the threshold current was inversely proportional to the OCF, and the lowest threshold current could also be obtained for the LWG and UWG thickness of $120 \mathrm{~nm}$. Therefore, the optimum thickness of the LWG and UWG layers was chosen to be $120 \mathrm{~nm}$ for subsequent simulations in this study. 


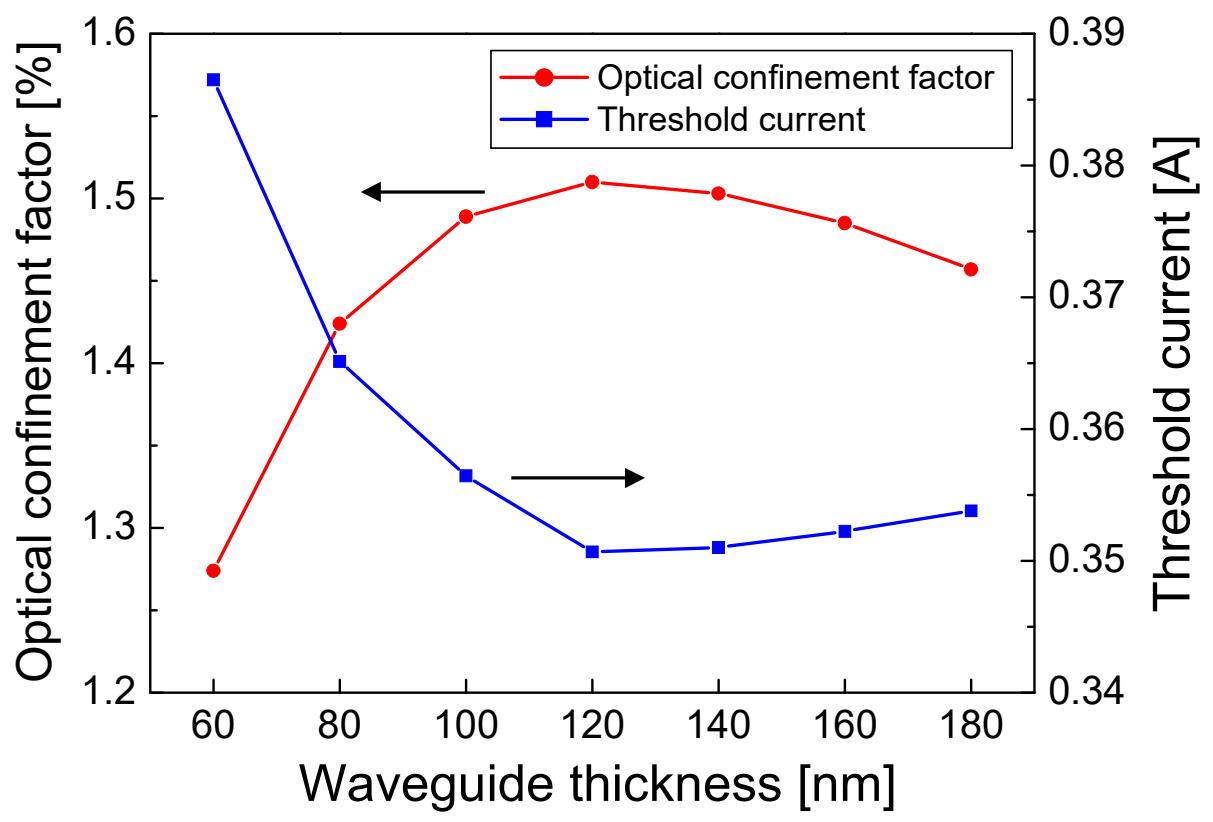

Figure 4. Optical confinement factor (left axis) and threshold current (right axis) as a function of the thickness below and above the MQW layers.

\subsection{Optimization of EBL}

Next, we investigated the effects of the $\mathrm{Al}$ composition and $\mathrm{Mg}$ doping concentration in the EBL on the LD performance. The role of the EBL is to prevent electron leakage from the MQW to the p-cladding layers. Therefore, the electron leakage current was first calculated for variation in the $\mathrm{Al}$ composition and doping concentration of the EBL. Figure 5 shows the portion of electron leakage current as a function of $\mathrm{Mg}$ doping concentration in the EBL for the $\mathrm{Al}$ compositions of $15 \%, 20 \%$, and $25 \%$. The portion of the leakage current, which is denoted as $f$, is defined as

$$
f=\frac{J_{n}^{y}(\mathrm{p}-\mathrm{AlGaN})}{J_{n}^{y}(\mathrm{n}-\mathrm{AlGaN})}
$$

where $J_{n}^{y}(\mathrm{n}-\mathrm{AlGaN})$ and $J_{n}^{y}(\mathrm{p}-\mathrm{AlGaN})$ are the vertical component of electron current density at the n-AlGaN and p-AlGaN cladding layer, respectively. As shown in Figure 5, $f$ decreased as both the doping concentration and the Al composition increased. To obtain an $f$ value $<1 \%$, the required $\mathrm{Mg}$ doping concentration was $\sim 5 \times 10^{19}, \sim 3 \times 10^{19}$, and $\sim 1.5 \times 10^{19} \mathrm{~cm}^{-3}$ for the $\mathrm{Al}$ compositions of $15 \%, 20 \%$, and $25 \%$, respectively. It can be observed from Figure 5 that a high $\mathrm{Mg}$ doping concentration and $\mathrm{Al}$ composition were advantageous for preventing electron leakage. In this simulation, the $\mathrm{Mg}$ doping concentration in the p-AlGaN cladding layer was fixed at $1.0 \times 10^{19} \mathrm{~cm}^{-3}$. However, it was found by separate simulations that the data in Figure 5 are almost independent of the $\mathrm{Mg}$ doping concentration. 




Figure 5. The portion of electron leakage current as a function of the Mg doping concentration in the AlGaN EBL for the $\mathrm{Al}$ compositions of $15 \%, 20 \%$, and $25 \%$.

Figure 6 shows the $L-I$ curves of the LDs for various Mg-doping concentrations from $1.0 \times 10^{18}$ to $5 \times 10^{19} \mathrm{~cm}^{-3}$. When the Al composition of the EBL was $15 \%$ (Figure $6 \mathrm{a}$ ), the output power at a high injection current decreased as the $\mathrm{Mg}$ doping concentration decreased because of increasing of the electron leakage with decreasing of the doping concentration, as shown in Figure 5. The output power did not decrease when the doping concentration was higher than $3 \times 10^{19} \mathrm{~cm}^{-3}$, which resulted from the negligible electron leakage for this high doping concentration. When the $\mathrm{Al}$ composition of the EBL was $20 \%$ (Figure $6 \mathrm{~b}$ ), the output power also decreased with the decreasing of the Mg doping concentration. However, the decrease in power was significantly reduced compared with that observed in the case of $15 \%-\mathrm{Al}$ composition. When the doping concentration was equal to or higher than $2 \times 10^{19} \mathrm{~cm}^{-3}$, the $L-I$ curves were almost the same for different doping concentrations. When the $\mathrm{Al}$ composition of the EBL was increased to $25 \%$ (Figure 6c), the $L-I$ curves were almost the same for all doping concentrations from $1.0 \times 10^{18}$ to $5 \times 10^{19} \mathrm{~cm}^{-3}$. However, a slight decrease in output power with the increasing of the $\mathrm{Mg}$ doping concentration was observed at a high current, which resulted from the increased optical absorption with the increasing of the doping concentration. Because the thickness of the EBL was only $15 \mathrm{~nm}$, the Mg doping in the EBL had a negligible influence on the optical absorption.

(a)

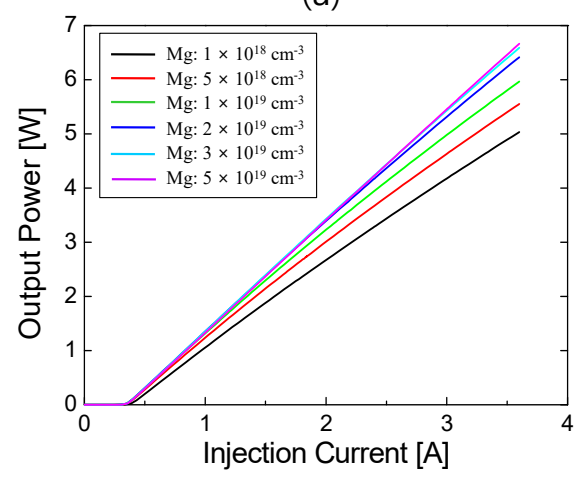

(b)

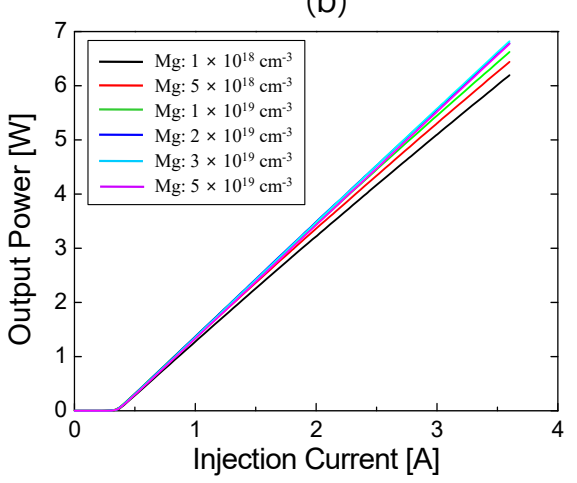

(c)

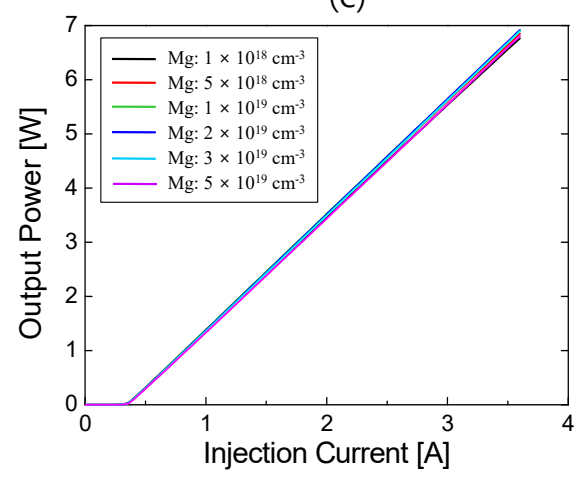

Figure 6. $L-I$ curves of LDs for various Mg doping concentrations from $1.0 \times 10^{18}$ to $5 \times 10^{19} \mathrm{~cm}^{-3}$ in the AlGaN EBL when the $\mathrm{Al}$ composition of the EBL was (a) $15 \%$, (b) $20 \%$, and (c) $25 \%$. 
The results in Figures 5 and 6 show that high $\mathrm{Al}$ composition and high $\mathrm{Mg}$ doping concentration in the EBL were advantageous for obtaining high output power by suppressing electron leakage. However, the high Al composition in the EBL could increase the forward voltage because the EBL also acted as an energy barrier for holes. In Figure 7a, the $V-I$ curves are compared for the $\mathrm{Al}$ compositions of $15 \%, 20 \%$, and $25 \%$. As expected, the forward voltage increased with the increasing of the $\mathrm{Al}$ composition of the EBL. This implies a trade-off relationship between the electron leakage current and forward voltage with variation in the $\mathrm{Al}$ composition of the EBL. Figure $7 \mathrm{~b}$ shows the WPE as a function of the $\mathrm{Mg}$ doping concentration for the $\mathrm{Al}$ compositions of $15 \%, 20 \%$, and $25 \%$. There existed a maximum WPE value for each $\mathrm{Al}$ composition as the doping concentration varied. The $\mathrm{Mg}$ doping concentration for which the maximum WPE was observed decreased from $4 \times 10^{19}$ to $2 \times 10^{19} \mathrm{~cm}^{-3}$ as the $\mathrm{Al}$ content increased from $15 \%$ to $25 \%$. As shown in Figure $7 \mathrm{~b}$, the maximum WPE of $38.5 \%$ could be obtained when the $\mathrm{Al}$ composition was $20 \%$ and the $\mathrm{Mg}$ doping concentration was $3 \times 10^{19} \mathrm{~cm}^{-3}$. Therefore, we chose these values as the optimum EBL parameters for the following simulations.

(a)

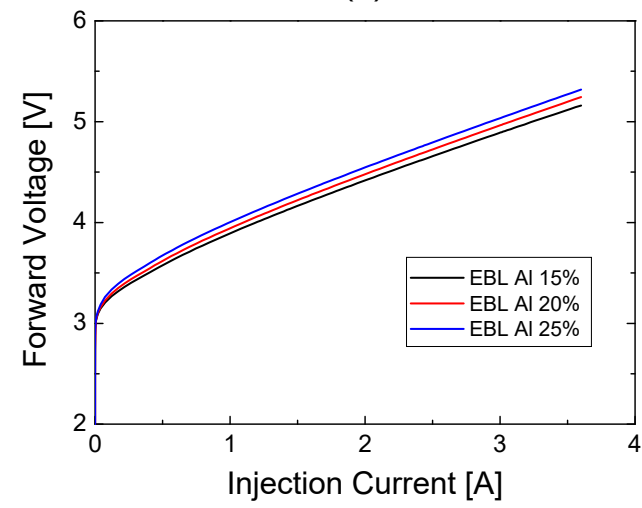

(b)

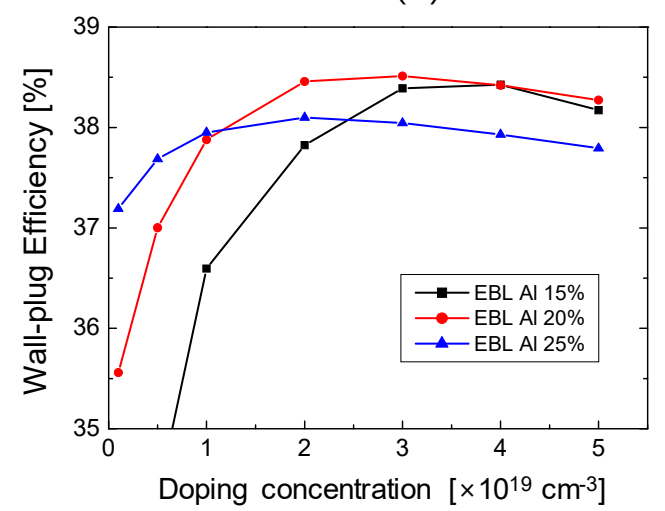

Figure 7. (a) $V-I$ curves for the EBL Al compositions of $15 \%, 20 \%$, and $25 \%$. (b) WPE as a function of the $\mathrm{Mg}$ doping concentration for the $\mathrm{Al}$ compositions of $15 \%, 20 \%$, and $25 \%$.

\subsection{Optimum Mg Doping Concentration in the p-AlGaN Cladding Layer}

In this subsection, we investigate the effect of the $\mathrm{Mg}$ doping concentration in the $\mathrm{p}-\mathrm{AlGaN}$ cladding layer on the $\mathrm{LD}$ device performance. To see the effect of the $\mathrm{Mg}$ doping on total internal optical loss, the modal loss was calculated as the Mg doping concentration varied. Figure 8 shows the modal loss as a function of the $\mathrm{Mg}$ doping concentration from $2 \times 10^{18}$ to $5 \times 10^{19} \mathrm{~cm}^{-3}$ in the p-cladding layer. The modal loss increased linearly from 4 to $8.4 \mathrm{~cm}^{-1}$ as the $\mathrm{Mg}$ doping concentration increased from $2 \times 10^{18}$ to $5 \times 10^{19} \mathrm{~cm}^{-3}$, indicating significant influence of the $\mathrm{Mg}$ doping on optical loss. The modal loss shown in Figure 8 is similar to that of a previously reported LD structure with an SE of 2 W/A [23].

Figure 9 shows the $L-I$ and $V-I$ curves for various $\mathrm{Mg}$ doping concentrations from $2 \times 10^{18}$ to $4 \times 10^{19} \mathrm{~cm}^{-3}$ in the p-cladding layer. According to the simulation results in Figures 4 and 7, the thicknesses of the LWG and UWG were set as $120 \mathrm{~nm}$, and the $\mathrm{Al}$ composition and $\mathrm{Mg}$ doping concentration of the $\mathrm{p}-\mathrm{AlGaN} \mathrm{EBL}$ were set as $20 \%$ and $3 \times 10^{19} \mathrm{~cm}^{-3}$, respectively. In Figure 9a, it can be seen that the output power decreased significantly as the $\mathrm{Mg}$ doping concentration increased because of the increased optical absorption loss in the p-AlGaN cladding layer with the increasing of the doping concentration. The output power relatively decreased by $\sim 24 \%$ as the doping concentration increased from $2 \times 10^{18}$ to $4 \times 10^{19} \mathrm{~cm}^{-3}$. In contrast, the forward voltage shown in Figure $9 \mathrm{~b}$ decreased with the increasing of the $\mathrm{Mg}$ doping concentration, resulting from the improved electrical conductivity in the p-AlGaN cladding layer with the increasing of the $\mathrm{Mg}$ doping concentration. At an injection current of $3 \mathrm{~A}$, the forward voltage decreased from 6.39 to $4.34 \mathrm{~V}$ as the doping concentrations increased from $2 \times 10^{18}$ to $4 \times 10^{19} \mathrm{~cm}^{-3}$. 




Figure 8. Modal loss of the LD structure as a function of Mg doping concentration.

(a)

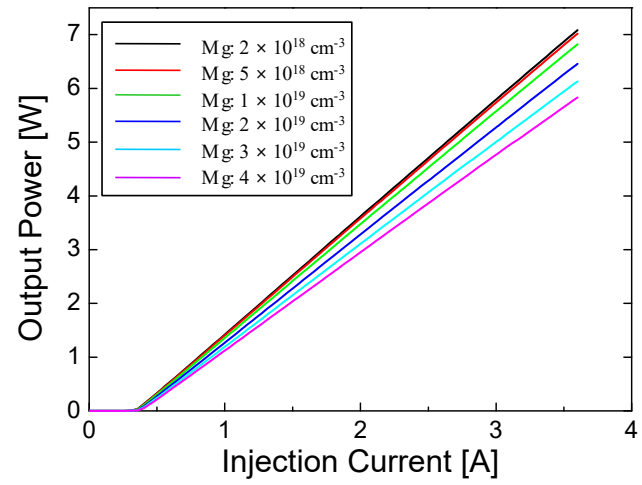

(b)

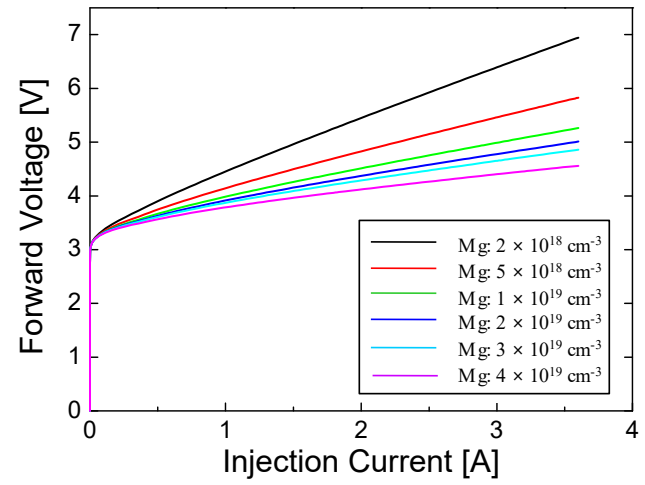

Figure 9. (a) $L-I$ and (b) $V-I$ curves for various Mg-doping concentrations from $2 \times 10^{18}$ to $4 \times 10^{19} \mathrm{~cm}^{-3}$ in the p-cladding layer.

As a result of the trade-off relationship between the output power and forward voltage with the variation of the $\mathrm{Mg}$ doping concentration, there existed an optimum $\mathrm{Mg}$ doping concentration where the maximum WPE could be obtained. Figure 10a shows the WPE as a function of the injection current for various $\mathrm{Mg}$ doping concentrations. When the doping concentration was $1 \times 10^{19}$ and $2 \times 10^{19} \mathrm{~cm}^{-3}$, the highest WPE was observed in a wide range of injection currents between 1 and $3.5 \mathrm{~A}$. In Figure 10b, the WPE values are plotted as a function of the $\mathrm{Mg}$ doping concentration in the $\mathrm{p}-\mathrm{AlGaN}$ cladding layer for the operation powers of 2,3,4, and $5 \mathrm{~W}$. When the operation power of an $\mathrm{LD}$ was $2 \mathrm{~W}$, the highest WPE of $\sim 37 \%$ could be obtained at a doping concentration of $1 \times 10^{19} \mathrm{~cm}^{-3}$. For the other operation powers of 3,4 , and $5 \mathrm{~W}$, the maximum WPE of $38.1-38.6 \%$ could be obtained at a doping concentration of $1.5 \times 10^{19} \mathrm{~cm}^{-3}$. The highest WPE was obtained as $38.6 \%$ when the output power was $4 \mathrm{~W}$ and the doping concentration was $1.5 \times 10^{19} \mathrm{~cm}^{-3}$. When the doping concentration was larger than $1.5 \times 10^{19} \mathrm{~cm}^{-3}$, the WPE decreased gradually with the increasing of the doping concentration, owing to the increased optical absorption in the p-AlGaN layer. The decrease in the WPE for doping concentrations $<1 \times 10^{19} \mathrm{~cm}^{-3}$ was attributed to the increase in the forward voltage due to the low hole concentration. Therefore, the optimum $\mathrm{Mg}$ doping concentration in the $\mathrm{p}-\mathrm{AlGaN}$ cladding layer for the highest WPE was found to be $1.5 \times 10^{19} \mathrm{~cm}^{-3}$, where the electrical conductivity and optical absorption were well balanced. 
(a)

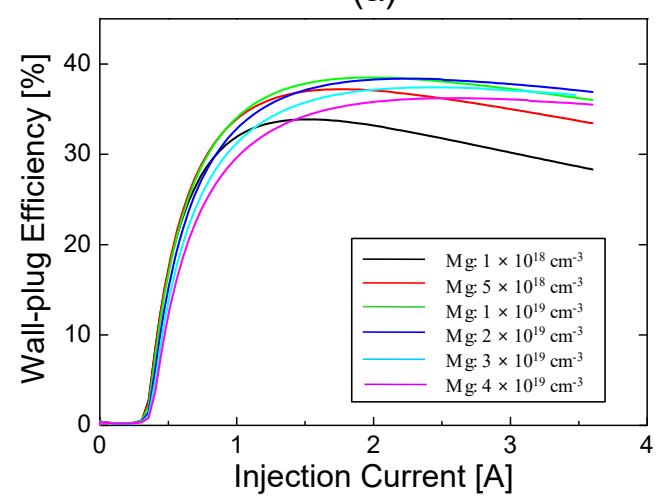

(b)

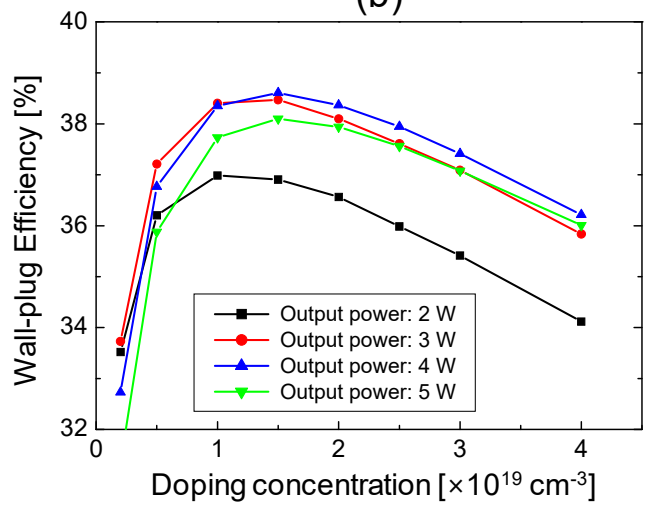

Figure 10. (a) WPE as a function of injection current for various Mg doping concentrations in the p-AlGaN cladding layer. (b) WPE as a function of Mg doping concentration in the p-AlGaN cladding layer for the output power of 2,3,4, and $5 \mathrm{~W}$.

As mentioned previously, the presented simulation results corresponded to the pulsed operation condition without self-heating effects. Nevertheless, it would be meaningful to discuss the self-heating effect on the optimum doping concentration. In general, both the output power and forward voltage decrease as the temperature increases [48-50]. As shown in Figure 9, the output power and voltage also decreased with the increasing of the $\mathrm{Mg}$ doping concentration. That is, the temperature influenced the output power and forward voltage in the same manner as the doping concentration in the p-AlGaN cladding layer. Consequently, if the self-heating effect was included, the optimum $\mathrm{Mg}$ doping concentration would be expected to shift toward a higher level as a result of the temperature rise.

\section{Conclusions}

In this study, we performed a systematic study to determine the optimum $\mathrm{Mg}$ doping concentrations in the p-AlGaN EBL and p-AlGaN cladding layers of InGaN blue LD structures using numerical simulations. First, the thickness of waveguides layers below and above the MQW layers was optimized to achieve a high OCF and low lasing threshold. Next, the effect of the AlGaN EBL on the device performance was investigated. The optimum Al composition and doping concentration were determined to be $20 \%$ and $\sim 3 \times 10^{19} \mathrm{~cm}^{-3}$, respectively, which showed a negligible electron leakage current and a high WPE. Finally, the effect of the Mg doping concentration in the p-AlGaN cladding layer was investigated. The highest WPE was obtained for the Mg doping concentration of $1.5 \times 10^{19} \mathrm{~cm}^{-3}$, where the forward voltage and output power were well balanced. For a blue LD with a threshold current density of $1 \mathrm{kA} / \mathrm{cm}^{2}$ and a slope efficiency of $2.1 \mathrm{~W} / \mathrm{A}$, a maximum WPE of $38.6 \%$ was obtainable under these optimum conditions. The simulation results revealed that the $\mathrm{Mg}$ doping concentration in p-type-doped layers has a significant influence on the WPE of InGaN blue LDs. The strategy to optimize the layer structures and doping concentrations of LDs presented in this study is expected to be advantageously applied in the development of high-power InGaN blue LD structures.

Author Contributions: Conceptualization, H.-Y.R.; methodology, C.O. and H.-Y.R.; software, C.O. and H.-Y.R.; validation, H.-Y.R.; investigation, C.O.; data curation, C.O.; writing-original draft preparation, C.O.; writing-review and editing, H.-Y.R.; supervision, H.-Y.R.; project administration, H.-Y.R.; funding acquisition, H.-Y.R. All authors have read and agreed to the published version of the manuscript.

Funding: This research was supported by the Basic Science Research Program through the National Research Foundation (NRF) of Korea, funded by the Ministry of Science and ICT (2019R1A2C1010160) and by the Technology Innovation Program (20015909) through the Korea Evaluation Institute of Industrial Technology (KEIT), funded by the Ministry of Trade, Industry \& Energy (MOTIE, Korea). 
Institutional Review Board Statement: Not applicable.

Informed Consent Statement: Not applicable.

Data Availability Statement: The data supporting the findings of this paper are available from the corresponding authors upon reasonable request.

Conflicts of Interest: The authors declare no conflict of interest. The funders had no role in the design of the study; in the collection, analyses, or interpretation of data; in the writing of the manuscript, or in the decision to publish the results.

\section{References}

1. Nakamura, S.; Senoh, M.; Nagahama, S.; Iwasa, N.; Yamada, T.; Matsushita, T.; Kiyoku, H.; Sugimoto, Y. InGaN-based multiquantum-well-structure laser diodes. Jpn. J. Appl. Phys. 1996, 35, L74-L76. [CrossRef]

2. Nagahama, S.; Yanamoto, T.; Sano, M.; Mukai, T. Wavelength dependence of InGaN laser diode characteristics. Jpn. J. Appl. Phys. 2001, 40, 3075-3081. [CrossRef]

3. Nakatsu, Y.; Nagao, Y.; Hirao, T.; Hara, Y.; Masui, S.; Yanamoto, T.; Nagahama, S. Blue and green InGaN semiconductor lasers as light sources for displays. Proc. SPIE 2020, 11280, 112800S.

4. Murayama, M.; Nakayama, Y.; Yamazaki, K.; Hoshina, Y.; Watanabe, H.; Fuutagawa, N.; Kawanishi, H.; Uemura, T.; Narui, H. Watt-class green $(530 \mathrm{~nm})$ and blue $(465 \mathrm{~nm})$ laser diodes. Phys. Status Solidi A 2018, 215, 1700513. [CrossRef]

5. Buckley, E. Laser wavelength choices for pico-projector applications. J. Disp. Technol. 2011, 7, 402. [CrossRef]

6. Wierer, J.J.; Tsao, J.Y.; Sizov, D.S. Comparison between blue lasers and light-emitting diodes for future solid-state lighting. Laser Photonics Rev. 2013, 7, 963-993. [CrossRef]

7. Ryu, H.Y.; Kim, D.H. High-brightness phosphor-conversion white light source using InGaN blue laser diode. J. Opt. Soc. Korea 2010, 14, 415-419. [CrossRef]

8. Chi, Y.C.; Hsieh, D.H.; Lin, C.Y.; Chen, H.Y.; Huang, C.Y.; He, J.H.; Ooi, B.; DenBaars, S.P.; Nakamura, S.; Kuo, H.C.; et al. Phosphorous diffuser diverged blue laser diode for indoor lighting and communication. Sci. Rep. 2015, 5, 18690. [CrossRef] [PubMed]

9. Watson, S.; Tan, M.; Najda, S.P.; Perlin, P.; Leszczynski, M.; Targowaski, G.; Grzanka, S.; Kelly, A.E. Visible light communications using a directly modulated $422 \mathrm{~nm}$ GaN laser diode. Opt. Lett. 2013, 38, 3792-3794. [CrossRef]

10. Lee, C.; Zhang, C.; Cantore, M.; Farrell, R.M.; Oh, S.H.; Margalith, T.; Speck, J.S.; Nakamura, S.; Bowers, J.E.; DenBaars, S.P. 4 Gbps direct modulation of $450 \mathrm{~nm}$ GaN laser for high-speed visible light communication. Opt. Express 2015, 23, 16232-16237. [CrossRef]

11. Wu, T.C.; Chi, Y.C.; Wang, H.Y.; Tsai, C.T.; Lin, G.R. Blue laser diode enables underwater communication at 12.4 Gbps. Sci. Rep. 2017, 7, 40480. [CrossRef] [PubMed]

12. Baumann, M.; Balck, A.; Malchus, J.; Chacko, R.V.; Marfels, S.; Witte, U.; Dinakaran, D.; Ocylok, S.; Weinbach, M.; Bachert, C.; et al. $1000 \mathrm{~W}$ blue fiber-coupled diode laser emitting at $450 \mathrm{~nm}$. Proc. SPIE 2019, 10900, 1090005.

13. Coffey, V.C. High-powered diode lasers-New, bright and blue. Opt. Photonics News. 2020, 28-35. [CrossRef]

14. Hagino, H.; Kawaguchi, M.; Nozaki, S.; Mochida, A.; Kano, T.; Takigawa, S.; Katayama, T.; Tanaka, T. High-power InGaN laser array with advanced lateral-corrugated waveguides. IEEE J. Quantum Electron. 2021, 57, 2600107. [CrossRef]

15. Zhong, Z.; Lu, S.; Li, J.; Lin, W.; Huang, K.; Li, S.; Cai, D.; Kang, J. Design and fabrication of high power InGaN blue laser diode over 8 W. Opt. Laser Technol. 2021, 139, 106985. [CrossRef]

16. Crump, P.; Wang, J.; Das, S.; Grimshaw, M.; Farmer, J.; DeVito, M.; Dong, W.; Crum, T.; Wise, D.; Feng, Y. >360 W and >70\% efficient GaAs-based diode lasers. Proc. SPIE 2005, 5711, 21-29.

17. Piprek, J. Comparative efficiency analysis of GaN-based light-emitting diodes and laser diodes. Appl. Phys. Lett. 2016, 109, 021104. [CrossRef]

18. Piprek, J. Analysis of efficiency limitations in high-power InGaN/GaN laser diodes. Opt. Quantum Electron. 2016, 48, 471. [CrossRef]

19. Uchida, S.; Takeya, M.; Ikeda, S.; Mizuno, T.; Fujimoto, T.; Matsumoto, O.; Goto, S.; Tojyo, T.; Ikeda, M. Recent progress in high-power blue-violet lasers. IEEE J. Sel. Top. Quantum Electron. 2003, 9, 1252-1259. [CrossRef]

20. Ryu, H.Y.; Ha, K.H.; Son, J.K.; Paek, H.S.; Sung, Y.J.; Kim, K.S.; Kim, H.K.; Park, Y.; Lee, S.N.; Nam, O.H. Comparison of output power of InGaN laser diodes for different Al compositions in the AlGaN n-cladding layer. J. Appl. Phys. 2009, 105, 103102. [CrossRef]

21. Chen, P.; Feng, M.X.; Jiang, D.S.; Zhao, D.G.; Liu, Z.S.; Li, L.; Wu, L.L.; Le, L.C.; Zhu, J.J.; Wang, H.; et al. Improvement of characteristics of InGaN-based laser diodes with undoped InGaN upper waveguide layer. J. Appl. Phys. 2012, 112, 113105. [CrossRef]

22. Liang, F.; Zhao, D.; Jiang, D.; Liu, Z.; Zhu, J.; Chen, P.; Yang, J.; Liu, W.; Li, X.; Liu, S.; et al. New design of upper waveguide with unintentionally doped InGaN layer for InGaN-based laser diode. Opt. Laser Technol. 2017, 97, 284-289. [CrossRef]

23. Kawaguchi, M.; Imafuji, O.; Nozaki, S.; Hagino, H.; Takigawa, S.; Katayama, T.; Tanaka, T. Optical-loss suppressed InGaN laser diodes using undoped thick waveguide structure. Proc. SPIE 2016, 9748, 974818. 
24. Hou, Y.; Zhao, D.; Liang, F.; Liu, Z.; Yang, J.; Chen, P. Enhancing the efficiency of GaN-based laser diodes by the designing of a p-AlGaN cladding layer and an upper waveguide layer. Opt. Mater. Express 2021, 11, 1780-1790. [CrossRef]

25. Schubert, E.F. Light-Emitting Diodes, 2nd ed.; Cambridge University Press: Cambridge, UK, 2006; pp. $145-149$.

26. Kioupakis, E.; Rinke, P.; Van de Walle, C.G. Determination of internal loss in nitride lasers from first principles. Appl. Phys. Express 2010, 3, 082101. [CrossRef]

27. Pourhashemi, A.; Farrell, R.M.; Cohen, D.A.; Speck, J.S.; DenBaars, S.P.; Nakamura, S. High-power blue laser diodes with indium tin oxide cladding on semipolar (202-1-) GaN substrates. Appl. Phys. Lett. 2015, 106, 111105. [CrossRef]

28. Li, X.; Zhao, D.G.; Jiang, D.S.; Chen, P.; Liu, Z.S.; Zhu, J.J.; Yang, J.; Liu, W.; He, X.G.; Li, X.J.; et al. The effectiveness of electron blocking layer in InGaN-based laser diodes with different indium content. Phys. Status Solidi A 2016, 213, 2223-2228. [CrossRef]

29. Wang, W.; Xie, W.; Deng, Z.; Liao, M. Improving output power of InGaN laser diode using asymmetric $\operatorname{In}_{0.15} \mathrm{Ga}_{0.85} \mathrm{~N} / \mathrm{In}_{0.02} \mathrm{Ga}_{0.98} \mathrm{~N}$ multiple quantum wells. Micromachines 2019, 10, 895. [CrossRef] [PubMed]

30. Cheng, L.; Li, Z.; Zhang, J.; Lin, X.; Yang, D.; Chen, H.; Wu, S.; Yao, S. Advantages of InGaN-GaN-InGaN delta barriers for InGaN-based laser diodes. Nanomaterials 2021, 11, 2070. [CrossRef] [PubMed]

31. LASTIP by Crosslight Software Inc Burnaby Canada. Available online: http:/ / crosslight.com (accessed on 1 October 2021).

32. Chang, Y.L.; Ludowise, M.; Lefforge, D.; Perez, B. Study of Mg diffusion during metalorganic chemical vapor deposition of GaN and AlGaN. Appl. Phys. Lett. 1999, 74, 688-690. [CrossRef]

33. Köhler, K.; Gutt, R.; Wiegert, J.; Kirste, L. Diffusion of Mg dopant in metal-organic vapor-phase epitaxy grown GaN and $\mathrm{Al}_{\mathrm{x}} \mathrm{Ga}_{1-\mathrm{x}}$ N. J. Appl. Phys. 2013, 113, 073514. [CrossRef]

34. Nam, O.H.; Ha, K.H.; Kwak, J.S.; Lee, S.N.; Choi, K.K.; Chang, T.H.; Chae, S.H.; Lee, W.S.; Sung, Y.J.; Paek, H.S.; et al. Characteristics of GaN-based laser diodes for post-DVD applications. Phys. Status Solidi A 2004, 201, 2717-2720. [CrossRef]

35. Fiorentini, V.; Bernardini, F.; Ambacher, O. Evidence for nonlinear macroscopic polarization in III-V nitride alloy heterostructures. Appl. Phys. Lett. 2002, 80, 1204-1206. [CrossRef]

36. Flory, C.A.; Hasnain, G. Modeling of GaN optoelectronic devices and strain-induced piezoelectric effects. IEEE J. Quantum Electron. 2001, 37, 244-253. [CrossRef]

37. Piprek, J. AlGaN polarization doping effects on the efficiency of blue LEDs. Proc. SPIE 2012, 8262, 82620E.

38. Park, S.I.; Lee, J.I.; Jang, D.H.; Kim, H.S.; Shin, D.S.; Ryu, H.Y.; Shim, J.I. Measurement of internal electric field in GaN-based light-emitting diodes. IEEE J. Quantum Electron. 2012, 48, 500-506. [CrossRef]

39. Ryu, H.Y.; Jeon, K.S.; Kang, M.G.; Yuh, H.K.; Choi, Y.H.; Lee, J.S. A comparative study of efficiency droop and internal electric field for InGaN blue light-emitting diodes on silicon and sapphire substrates. Sci. Rep. 2017, 7, 44814. [CrossRef]

40. Farahmand, M.; Garetto, C.; Bellotti, E.; Brennan, K.F.; Goano, M.; Ghillino, E.; Ghione, G.; Albrecht, J.D.; Ruden, P.P. Monte Carlo simulation of electron transport in the III-nitride wurtzite phase materials system: Binaries and ternaries. IEEE Trans. Electron. Devices 2001, 48, 535-542. [CrossRef]

41. Piprek, J. Semiconductor Optoelectronic Devices; Academic Press: London, UK, 2003; pp. 187-211.

42. Chen, J.R.; Wu, Y.C.; Ling, S.C.; Ko, T.S.; Lu, T.C.; Kuo, H.C.; Kuo, Y.K.; Wang, S.C. Investigation of wavelength-dependent efficiency droop in InGaN light-emitting diodes. Appl. Phys B 2010, 98, 779-789. [CrossRef]

43. Zhang, L.Q.; Jiang, D.S.; Zhu, J.J.; Zhao, D.G.; Liu, Z.S.; Zhang, S.M.; Yang, H. Confinement factor and absorption loss of AlInGaN based laser diodes emitting from ultraviolet to green. J. Appl. Phys. 2009, 105, 023104. [CrossRef]

44. Muziol, G.; Turski, H.; Siekacz, M.; Sawicka, M.; Wolny, P.; Perlin, P.; Skierbiszewski, C. Determination of gain in AlGaN cladding free nitride laser diodes. Appl. Phys. Lett. 2013, 103, 061102. [CrossRef]

45. Ryu, H.Y. Investigation into the anomalous temperature characteristics of InGaN double quantum well blue laser diodes using numerical simulation. Nanoscale Res. Lett. 2017, 12, 366. [CrossRef] [PubMed]

46. Piprek, J.; Li, S. Electron leakage effects on GaN-based light-emitting diodes. Opt. Quantum Electron. 2011, 42, 89-95. [CrossRef]

47. Neamen, D.A. Semiconductor Physics and Devices, 4th ed.; McGraw Hill: New York, NY, USA, 2012; pp. $131-135$.

48. Xi, Y.; Gessmann, T.; Xi, J.; Kim, J.K.; Shah, J.M.; Schubert, E.F.; Fischer, A.J.; Crawford, M.H.; Bogart, K.H.; Allerman, A.A. Junction temperature in ultraviolet light-emitting diodes. Jpn. J. Appl. Phys. 2005, 44, 7260-7266. [CrossRef]

49. Ryu, H.Y.; Ha, K.H.; Chae, J.H.; Nam, O.H.; Park, Y.J. Measurement of junction temperature in GaN-based laser diodes using voltage-temperature characteristics. Appl. Phys. Lett. 2005, 87, 093506. [CrossRef]

50. Onwukaeme, C.; Choi, W.J.; Ryu, H.Y. Accurate determination of junction temperature in a GaN-based blue light-emitting diode using nonlinear voltage-temperature relation. Opt. Quantum Electron. 2021, 53, 513. [CrossRef] 